\title{
Sorgen (ernst) nehmen: Die Covid-Impfung
}

\author{
Heil oder Unheil Die Impfung gegen Covid-19 ist momentan die einzige Mög- \\ lichkeit, die Pandemie zu beenden. Und doch gibt es Unsicherheit und Ängste \\ - auch bei in der Pflege Tätigen. Eine Auseinandersetzung mit den wichtigsten
} Argumenten.

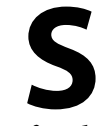

eit dem 21.12.2020 ist mit dem BioNTech/Pfizer-Impfstoff Comirnaty der erste Impfstoff gegen SARS-CoV2 in Deutschland zugelassen, am 06.01.2021 folgte die Zulassung für den Moderna-Impfstoff.

Beiden gemein ist die Tatsache, dass es sich um mRNA-Impfstoffe handelt und diese erstmals in der Historie der Impfungen eingesetzt werden. Das sorgt für Unsicherheit und Ängste, und häufig werden von Skeptikern falsche Behauptungen verbreitet, welche von medizinischen Laien oftmals nicht nachvollzogen oder geprüft werden können. Aber auch für Fachpersonal aus Medizin und Pflege sind die neuen Methoden durch widersprüchliche Darstellungen in sozialen Netzwerken nicht sofort schlüssig. In der Folge sinkt die Impfbereitschaft, was aber angesichts der aktuellen schwierigen Pandemie-Lage nachteilig ist.

Um die Sorgen der Impfung gegenüber zu nehmen, ist es notwendig, sie ernst zu nehmen. Denn bisher noch nicht eingesetzte Mechanismen bei der Impfung, eine schnelle Zulassung des Vakzins und in die Welt gesetzte Scheinargumente gegen die Impfung verbreiten sich gerade in den sozialen Medien rasant. Dabei können nahezu alle Argumente gegen die Impfung widerlegt werden.

\section{Verändert der Impfstoff die Gene?}

Bei den beiden in Deutschland zugelassenen Impfstoffen handelt es sich um sogenannte mRNA-Impfstoffe. Die RNA (Ribonukleinsäure) ist der Träger der genetischen Information in vielen Viren und ist nichts anderes als ein Bauplan darüber, wie das Virus aufgebaut ist. Das Coronavirus dockt mit seinem Spike-Protein, das es an der Oberfläche trägt, an menschliche Zellen an, schleust seine RNA in die Zelle und lässt anhand des Plans neue Viren herstellen.

Wir als Menschen haben die DNA (Desoxyribonukleinsäure) als Erbinformation, die sich gut geschützt im Zellkern befindet. Die Impfung an sich ist nun nichts anderes, als ein kleines Stückchen des Viren-Bauplans, und zwar der des Spike-Proteins. Damit der Bauplan stabil bleibt, wird er noch mit kleinen Kappen an den Enden versehen und in Lipidnanopartikel verpackt. Diese LNP sind kleine Fetttröpfchen, die dann in die Zelle eingeschleust werden.
LPN kennen wir aus unserem Körper: das LDL-Cholesterin ist nichts anders, als ein Lipidtröpfchen, das Cholesterin transportiert. Die Sorge vieler Menschen ist nun, dass sich die RNA in unsere menschliche DNA einbauen könnte. Das kann aber nicht passieren, denn uns fehlt der Mechanismus hiefür. Es folgt nun gerne das Argument, dass manche Viren, zum Beispiel das HI-Virus, eine sogenannte Reverse Transkriptase mitbringen - ein Enzym, das die RNA in unsere menschliche DNA einbaut. Das stimmt zwar, dennoch kann diese Reverse Transkriptase nur diese spezifische RNA umwandeln, es ist kein Universalwerkzeug.

\section{Kontakt mit dem Zellkern ausgeschlossen}

Ferner besitzen viele Viren, auch das banale Schnupfenvirus (Rhinovirus) die RNA als Erbsubstanz, und weder beim Schnupfennoch beim Coronavirus gibt es Sorgen, dass sich die RNA in unserer DNA einnisten könnte. Folglich wird dies auch nicht mit einem kleinen Teilstück des Bauplans, den wir durch die Impfung eingebracht bekommen, passieren.

Die mRNA der Impfung kommt nicht einmal in Kontakt mit dem Zellkern, sondern wird in das Zellplasma aufgenommen, und zwar auch nur in die Zellen, die sich rund um die Einstichstelle befinden. Dort wird sie abgelesen und produziert das Spike-Protein, welches an der Oberfläche unserer Zellen dem Immunsystem präsentiert wird. Dieses kann sich dann gegen Viren mit diesen Oberflächenstrukturen „schulen“. Die abgelesene mRNA wird abgebaut.

\section{Nebenwirkungen gibt es - wie bei jeder Impfung}

Jede Impfung aktiviert unser Immunsystem und fordert es heraus, Antikörper gegen ein Antigen von Viren oder Bakterien zu bilden. Daher sind die üblichen Nebenwirkungen einer Impfung Schmerzen und Schwellungen an der Einstichstelle, weil hauptsächlich dort die Impfung wirkt. Außerdem können die Lymphknoten anschwellen, Kopf- und Gliederschmerzen auftreten oder manchmal auch leichtes Fieber. Wie bei einem Infekt auch, nur in abgeschwächter Form. Nach zwei bis drei Tagen ist der Prozess abgeschlossen und die Impfreaktion klingt ab. Zu beachten gilt insbesondere für Allergiker, dass es Unverträglichkeiten gibt. Diese Reaktionen treten 
innerhalb von 15 bis 20 Minuten nach der Injektion auf, so dass die Impflinge für diesen Zeitraum beobachtet werden sollten. Ferner sind im Verlauf der Phase-III-Studie des Comirnaty-Impfstoffes (BioNTech/Pfizer) vier Fälle einer Fazialisparese (Gesichtslähmung) aufgetreten. Die vier Fälle entsprechen der Hintergrundinzidenz. Das heißt, man erwartet bei einer vergleichbaren Population auch ohne jegliche Impfung diese Anzahl von Fällen einer Fazialisparese, dennoch muss natürlich beobachtet werden, ob weitere Fälle gemeldet werden. Für sehr alte (über 85 Jahren), sehr gebrechliche Patienten mit schweren Vorerkrankungen (z.B. schwere Herzinsuffizienz, Demenz, schwere Lungenerkrankungen) gilt eine sorgfältige Nutzen-Risiko-Abwertung.

\section{Impfstoff ist sicher und wirksam}

Gerne wird als Argument gegen die Impfung angeführt, dass er viel zu schnell zugelassen wurde. Doch der mRNA-Impfstoff wurde in Deutschland in einem regulären Zulassungsverfahren geprüft. Dass die Zulassung deutlich schneller ging, als bei anderen Impfstoffen, liegt zum einen an der Art des Verfahrens: In einem „Rolling review“-Verfahren wurden Daten der Studie parallel zu ihrer Durchführung ausgewertet. Normalerweise werden Daten erst gesammelt und anschließend begutachtet. Zum anderen konnten innerhalb eines kurzen Zeitraumes fast 43.000 Studienteilnehmer eingeschlossen werden. Das sind immense Zahlen, die in der Regel bei der Zulassung einer Impfung nicht in der Kürze der Zeit zustande kommen. In den letzten Monaten gab es diese Zahlen - pandemiebedingt.

Die mRNA-Impfstoffe werden bereits seit Jahren erforscht und sind kein Neuland, wenn es auch das erste Mal ist, dass ein mRNAVakzin am Menschen zugelassen ist.

\section{Die Impfung macht nicht unfruchtbar}

Ein weiteres Scheinargument gegen die Corona-Impfung ist die Behauptung, die Impfung könne unfruchtbar machen. Angeführt wird eine angebliche Ähnlichkeit zwischen dem Spike-Protein und einem Protein, das für den Aufbau von plazentarem Gewebe wichtig ist und Syncytin-1 heißt. Die Antikörper gegen das Spike-Protein sollen nun an dem plazentaren Gewebe andocken und es zerstören, heißt es.

Um zu verstehen, warum das nicht der Fall ist, ein kurzer Einblick in den Aufbau eines Proteins. Ein Protein besteht aus langen Ketten von Aminosäuren, von denen es zwanzig Stück gibt, und die als Buchstaben abgekürzt werden. Wenn man den Aufbau der beiden Proteine als „Buchstabenkette“ vergleicht, sind die Ähnlichkeiten gering. Wenige Stellen stimmen mit ihren Aminosäuren überein und zwischen Bereichen mit etwas mehr Ähnlichkeit finden sich Abschnitte, die keine Übereinstimmungen haben. Die Übereinstimmungen sind also zufällig. Vergleicht man die Aminosäurekette des Spike-Proteins mit der eines Rhino-Virus oder eines Rota-Virus, finden sich ebenfalls zufällig gleich lautende Abschnitte von wenigen (bis drei Stück) Aminosäuren. Eine Übereinstimmung findet also auf molekularer Ebene nur vereinzelt satt. In etwa so, wie sich Buchstaben auf einer Seite eines Buches mit denen auf der nächsten Seite gleichen, und dennoch ein anderes Wort ergeben.

Ferner muss dazu gesagt werden, dass mit dem Unfruchtbarkeitsargument gerne viel Unsicherheit gesät wird, denn wenige
Ängste erschüttern Frauen derart, wie die Angst um den (potentiellen) Nachwuchs. Geistliche vieler Religionen machen sich diese Ängste zu nutzen, um Impfungen zu verunglimpfen.

Gäbe es Unfruchtbarkeit durch die Impfung, müsste auch das Coronavirus selbst sie auslösen. Und bei Millionen von an Covid-19 erkrankten Frauen weltweit wurde dies nicht festgestellt. Darüber hinaus müsste dann auch die Angst vor Unfruchtbarkeit bei jedem Schnupfen bestehen, und dies ist ja bekanntermaßen nicht der Fall.

\section{I $\quad$ FAZIT FÜR DIE PFLEGE}

\begin{abstract}
Aktuell sind mehrere Millionen Menschen gegen Corona geimpft worden. Dass auch schwere Nebenwirkungen auftreten können, haben Impfungen und Medikamente gemein.
\end{abstract}

Gerne wird mit den Unsicherheiten und Ängsten der Menschen gespielt. Falsche Aussagen (fake news) finden über soziale Medien rasch Verbreitung. Doch Scheinargumente, verziert mit Fachbegriffen, lassen sich nicht immer auf den ersten Blick entkräften und benötigen Recherchearbeit. Dass eine Covid-Infektion tödlich sein kann, auch für Junge und bis dato Gesunde, wird gerne bestritten.

Die Impfung ist eine sichere und wirksame Methode, der Pandemie Einhalt zur gebieten. Ob man nach einer Impfung im Falle einer Infektion noch infektiös ist, ist Gegenstand aktueller Forschung. Solange ist die Einhaltung der aktuellen Regelungen wichtig.

Durch die Impfung werden schwere Verläufe unwahrscheinlicher und die Krankenhäuser entlastet.

Die Literaturliste erhalten Sie im HEILBERUFE eMag und online auf springerpflege.de

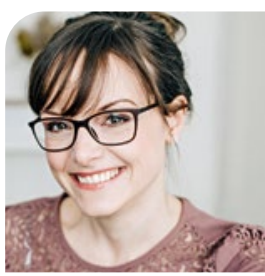

\section{Dr. med. Ulrike Koock}

Ärztin i.W. Allgemeinmedizin 61130 Nidderau ulrike@koock.net

\section{+ WEB-TIPP}

\section{Seriöse Quellen zu überprüfbaren Fakten:}

rki.de/SharedDocs/FAQ/COVID-Impfen/gesamt.html

pei.de/DE/newsroom/dossier/coronavirus/ coronavirus-node.html

gesundheitsinformation.de/ suche/\#searchQuery=query=corona 